\title{
Comienzos del 34: una visión periodística de la época
}

\author{
MANUEL BARAJA MONTAÑA
}

El 18 de diciembre de 1933 quedaba constituido el gobierno presidido por Lerroux que apoyado en una sólida mayoría parlamentaria, iba a emprender la tarea de rectificar la legislación republicana de los dos años precedentes y además sin ninguna reserva: "se puso de moda la frasesita republicanizar la república o lo que es igual; dejar en los Ministerios a los que eran afectos al gobierno republicano-socialista. Todo aquel que no gritara a dos pulmones que el señor Azaña era pontífice infalible, era sospechoso de reacción y de monarquismo. la consecuencia era fatal: a la calle.....Urge revisar los motivos en que se inspiró ese criterio ministerial para separar a los funcionarios. Nada de revanchas ni sectarismos. Pero nada de impunidades. Que sepa el país el porqué de muchas cosas que se decían revolucionarias y que en la realidad no pasaban de actos de poder inspirados en razones de puro capricho personal.1

Que el régimen republicano fuera el de una pacífica convivencia entre los españoles dependía, pues, de la capacidad de la derecha para definirse positivamente y de la izquierda para aceptar tal definición. Que las cosas no iban a resultar fáciles era algo que sabía Alejandro Lerroux, como viejo y experimentado político que era. Y mucho de esto era porque las izquierdas no habían asimilado bien la derrota, identificando su propia 'gestión de gobierno con la supervivencia de la república y desde que tuvieron que abandonar el poder mostraban una manifiesta proclividad revolucionaria. Lo cierto es que el socialismo no hacía ningún secreto de sus propósitos subversivos y se percibía un acusado proceso de radicalización en el partido socialista, donde Besteiro era desplazado de la UGT y la línea dura era adoptada por Largo Caballero e incluso por Prieto quién el 4 de febrero en un mitin sentenciaba: "Hágase cargo el proletariado del Poder y haga de España lo que España se merece. Para

(1) Diario de Cádiz, 15 de enero de 1934 
ello no debe titubear y si es preciso verter sangre, debe verterla.. 2 Palabras de las que Prieto se lamentaría años más tarde.

Situación ésta que era perfectamente detectada por la prensa local ${ }^{3}$ aunque quienes llenaban las portadas de los periódicos eran otras noticias: el estreno del Divino Impaciente de José María Pemán y la llegada al castillo de Santa Catalina del general Sanjurjo procedente del penal de Santoña ${ }^{5}$, apareciendo una entrevista con el general en el Diario de Cádiz el 12 de enero y otra el 14 de febrero en La Información. Y sobre todo el problema de la falta de trabajo en Cádiz: :En los astilleros de Echevarrieta una vez que se termine la construcción del petrolero para la Campsa el próximo 15 de marzo, se verá en la necesidad de prescindir de 500 obreros de los 600 que actualmente trabajan. Que el problema es pavoroso, no hay que dudarlo, pues el fantasma del hambre no solo amenaza a esos obreros que han de ser despedidos, sino a los que confiaban trabajar ante prometidas concesiones. ${ }^{6}$

Quizás fuese Cádiz uno de los lugares de España donde el proyecto de ley presentado por Gil Robles para combatir el paro involuntario fuese hacer más falta, ya que el futuro de Matagorda era alarmante ante la falta de trabajo como expone en una serie de artículos el alcalde Manuel de la Pinta desmenuzando las razones que han desembocado en esa situación $n^{8}$ y eximiéndose de toda responsabilidad. Postura que no comparte La Información como podemos leer en un artículo del día 11 de febrero titulado Se han burlado de Cádiz: *...pero lo que es incalificable, lo que no tiene precedente, lo que no puede admitirse es que una comisión de trabajadores que llega hasta la persona que debe representar al pueblo, con la agonía y la tristeza de quién ve su hogar amenazado por la miseria, se le conteste con gran tranquilidad que se han burlado de Cádiz, es decir, del pueblo que esa persona representa; pero que, a pesar de ello, él sigue representándolo, sin que le moleste el trallazo recibido.

Realmente la prensa gaditana en aquellos momentos era altamente pesimista y todo eran reproches al gobierno radical. El panorama se mirase por donde se mirase era sombrío y aciago: sobre la juventud afirmaba: "lo vemos en las carteleras de los cines, lo vemos en los anuncios de la prensa y en los escaparates de las librerías. Se está desarrollando, mientras muchos hombres que deberían poner remedio

(2) $\mathrm{H}^{2}$ General de España y América,Vol. XVII, Coord. Ruiz Manjón-Cabeza, O. pág. 49

(3) La Información, 28 de enero y 1 de febrero de 1934

(4) Lá Información, 3 de febrero de 1934

(5) La Información, 6,7 y 10 de enero y Diario de Cádiz 10 de enero de 1934

(6) Diario de Cádiz, 10 de enero de 1934

(7) Diario de Cádiz, 14 de enero de 1934

(8) Diario de Cádiz, 16, 17, 18, 20 y 21 de enero de.1934 
sestean, la más espantosa, la más perjudicial y la más eficaz campaña que jamás se emprendió en nuestra Patria contra el catolicismo. La invasión sarracena fue una cosa gravísima, pero la invasión sexual en nuestra sociedad es realmente catastrófica....Está claro que en España hay en el momento actual una organización pensada, fría, muy bien calculada y dirigida por las logias masónicas para desmoralizar toda nuestra juventud.9 y de la actuación del gobierno y el ambiente en las calles nos ofrecía esta perspectiva: y mientras tanto el orden social y el orden político es poco menos que arrastrado por las calles. Los atentados personales se suceden sin interrupción; se dispara contra la gente porque lee periódicos de la extrema derecha o de la extrema izquierda. El diálogo se interrumpe para dejar paso a la seca detonación de la pistola. Desde las tribunas se deja oír el lenguaje inaudito: saldremos a la calle, dice Prieto. Replica Gil Robles a la misma hora: si quieren salir a la calle allí nos encontraremos. Mientras, el Poder contempla, como un emperador romano, este juego de gladiadores. Y en el Parlamento la iniciativa no se sabe de quién parte: las derechas acosan; las izquierdas apremian y el Gobierno vive de la misericordia..10

A mediados de febrero y a nivel local entresacamos estas noticias: la construcción en Cádiz de una nueva parroquia, la de la Palma por desmembración de la de San Lorenzo" ${ }^{11}$; el triunfo de Manuel de Falla en la Scala de Milán ${ }^{12}$ y la prohibición de usar máscaras en los Carnavales. ${ }^{13}$

De resonancia nacional, el dos de marzo, La Información en grandes titulares publica la noticia de que Lerroux presentó al jefe del Estado la dimisión de dos ministros y Alcalá Zamora le indicó la conveniencia de que la crisis fuese total. Iniciaba así Martínez Barrios una disidencia que le llevaría a la fundación del partido radical-demócrata.

La crisis se saldaba con la sustitución de tres ministros (Martínez Barrios, Lara y Pareja Yébenes) con lo cual era evidente que el Gabinete quedaba más homogéneo y con un leve desplazamiento hacia la derecha. Iba a comenzar un período de inestabilidad gubernamental que tanto contribuyó a su estirilidad, ya que aquel cambio, como otros muchos, no solucionaría nada y ssi difícil era la situación del Gobierno cuando hace pocos días el señor Lerroux se encargó de echarle un remiendo, no lo es mucho mejor ahora, pues el remiendo echado ha sido del mismo material y las puntadas parece que no muy firmes. Se ha de encontrar ahora con

(9) La Información, 7 de febrero de 1934

(10) La Información, 8 de febrero de 1934

(11) La Información, 22 de febrero de 1934

(12) La Información, 10 de febrero de 1934

(13) La Información, 11 de febrero de 1934 
unos conflictos cuya gravedad a nadie puede ocultársele, y aunque todos ellos podrían resolverse con sólo hacer cumplir la ley, mucho nos tememos que el señor Lerroux no se decida a ello y prefiera continuar su plan de condescendencia con las izquierdas, restándose al conducirse así los votos que en el Parlamento pudieran otorgarle las derechas. La campaña que los socialistas le preparan es de verdadero encono; es de aquellas en que puede decirse que van a jugarse la última carta, y. por lo tanto no omitirán medio para conseguir una victoria. Mueven ya a sus huestes, y preparan toda clase de huelgas, ilegales desde luego, y sin preocuparse del resultado que ello pueda traer para España.. ${ }^{14}$

Preocupación, que en opinión del conde de Rodezno, ya nadie tenía en España porque ‘a España ya no le preocupan ni los debates políticos, ni las contiendas entre esas familias o gremios que la han llevado al estado en que se encuentra. Los españoles estamos ya bien cansados de esperar ver cumplidos algunos siquiera de tantos ofrecimientos; el problema de España es ya tan grave, que no puede remediarse con los mismos sistemas tan desacreditados; España necesita batirse no en defensa del régimen, ni en defensa de la legalidad republicana; necesita batirse de una vez, en defensa de la Sociedad, de la Civilización Cristiana y frente al materialismo racionalista.de los sicarios de Lenin. ${ }^{15}$

-Si como dicen los gitanos los que acaban bien han de empezar mal, es indudable que a este gobierno le esperan días de gloria. Todas las opiniones coinciden en señalar el disgusto, la contrariedad y el desencanto. ${ }^{16}$

Y la andadura no podía empezarla peor el nuevo gobierno pues la primera medida que tuvo que tomar fue implantar el estado de alarma en toda España y ‘ya los ciudadanos que vivimos a cara descubierta, los que no celebramos reuniones secretas, los que cumplimos la Ley en todo momento, tenemos que privarnos hasta de reunirnos en público, precisamente por culpa de aquellos que en privado lo hacen. Ahora lo que es necesario, es que ya que se proclamó el estado de alarma, se cumpla la Ley para el que de ella se salga. Que no se siga considerando esa otra alarma en que unos cuantos tienen desde hace tiempo al País, y que no sirva tampoco para que a la sombra de esa ley de excepción se agrupen para sestear los que tienen el deber de no alarmar ellos con su inactividad, ni permitir a los otros que alarmen con sus actos., ${ }^{17}$

Y si la situación ya era de por sí complicada vino a enmarañárlo todo mucho más el conflicto de los catalanes con el Gobierno central que estallaría a partir de la aprobación por el Parlamento catalán, en marzo de 1934, de

(14) La Información, 6 de marzo de 1934

(15) La Información, 7 de marzo de 1934

(16) Diario de Cádiz, 7 de marzo de 1934

(17) La Información, 8 de marzo de 1934 
una ley de Cultivos que establecía las condiciones para que los rabassaires se transformasen en plenos propietarios de las tierras que cultivaban.

La ley no era en modo alguno radical, ni, desde luego, tenía nada de socialista. Companys pretendía que los miles de pequeños agricultores, cuya principal cosecha era la de uva, tuviesen acceso a la propiedad de las tierras arrendadas. Hasta ahora el propietario y el arrendatario se dividían los beneficios a medias y el arrendamiento duraba hasta que morían las tres cuartas partes de las viñas; por este tipo de contrato, de rabassa morta, los campesinos eran conocidos como rabassaires, que representaban votos seguros para la Esquerra, mientras que los propietarios lo eran para la LLiga.

El conflicto desembocó en un pulso entre el Gobierno de Madrid, formado por hombres de centro-derecha y el Gobierno de Barcelona, dominado cada vez más fuertemente por Esquerra Republicana. El problema surgió al suscitarse la cuestión de si la regulación de los contratos de cultivo correspondía al derecho civil (y, entonces, entraba dentro del ámbito de las competencias autonómicas) o al social (siendo en este caso el parlamento central, y no el catalán, el que debiera regular sobre la materia). Sea como fuese los propietarios encuadrados en el Instituto Agrícola Catalán de San Isidro consiguieron que la LLiga presentase un recurso de inconstitucionalidad.

$\mathrm{El}$ asunto se fue envenenando de tal manera que se olvidó el sentido que inicialmente tenía: no era visto ya como un problema social, sino como un pleito autonómico. Pero veamos qué ocurría en Cádiz y cuál era la situación del Gobierno mientras el Tribunal de Garantías Constitucionales deliberaba si era legal o no el texto aprobado por el Parlamento catalán.

En Cádiz, la prensa haciéndose eco de la opinión pública se lamentaba que no fuesen a salir procesiones en Semana Santa rompiendo con una tradición de muchos años y en contra del sentimiento de la mayoría de los gaditanos, amén de los perjuicios económicos que conllevaba el no sacar en procesión a las distintas imágenes, ya que alrededor de ellas muchos necesitados sacaban un dinero vital para seguir subsistiendo: *Han comenzado en toda España las fiestas de Semana santa. Los clásicos tragacuras están indignadísimos. ¿Pero ha venido la República? se preguntan rasgándose las vestiduras. Se han pasado la vida pidiendo libertad de cultos, y cuando la Constitución declara al Estado laico y el ejercicio del culto religioso libre, truenan contra la libertad. España es un país católico, se quiera o no se quiera por algunos. Pero hay gente que no se enteran. Les falta serenidad para mirar de frente a la realidad. Han salido las procesiones. No ha ocurrido ninguna catástrofe. Sevilla y Murcia 
ganarán mucho dinero y comerán muchos pobres, bastantes más que con el crudo laicismo en Cádiz. ${ }^{18}$

$\mathrm{Y}$ todo esto cuando la ciudad estaba viviendo unos tiempos de recesión económica realmente preocupantes, pues una de las líneas marítimas más importantes que recalaba en Cádiz iba a ser suprimida, la denominada Mediterráneo-Lisboa-Vigo-Nueva York-Cuba-Panamá.

*No podemos comprender, decía La Información el 14 de marzo, cómo se hacen o se toman estas determinaciones en asuntos de tanta importancia; no podemos comprenderlo a no ser que sean los de fuera los que vienen a imponer en nuestro País lo que más a ellos les interese."

Y eso, sigue diciendo el periódico, lo único que traería sería la "correspondiente hijuela de miseria para varios sectores del comercio, de la industria, y del trabajo en nuestros muelles. Con otro borrón más, y a nuestros muelles atracarán los vaporcitos que hacen la travesía a los puertos."

Y la verdad es que con datos en la mano la línea no parecía deficitaria: ‘El Magallanes llegó con carga numerosísima tomada en sus escalas del Mediterráneo y con las que tomará en Cádiz, Lisboa y Vigo irá completamente abarrotado, además de doscientos pasajeros. ${ }^{19}$

Vemos pues que había muchas posibilidades de que se incrementase el paro, siendo éste otro tema que estaba bastante oscuro y que levantaba fuertes críticas en la ciudad ya que se sospechaba que sus fondos no se utilizaban en la forma correcta: :....encaminé mis gestiones a averiguar las obras que se habían realizado con dichos fondos que ascendian aproximadamente al medio millón de pesetas y por parte del señor alcalde y otros vocales se me manifestó que no lo sabían y que era muy difícil averiguarlo y por el personal de las oficinas se me informó de la imposibilidad de determinar las obras en que se habían invertido los fondos del paro forzoso, pues no constaban en las dependencias órdenes de obras, acuerdos municipales, ni de la Comisión, ni existían certificaciones de obras como es preceptivo y sólo aparecían relaciones de jornales que además algunos no alcanzaban el mínimo establecido en las bases de trabajo vigentes. ${ }^{20}$

Hemos visto, pues, que durante los meses de enero, febrero y marzo se fueron acumulando muchas dificultades y ennegreciéndose el futuro. Fusionados Falange y las JONS ya no disimulaban que su dialéctica eran los puños y las pistolas. Tanto en la Universida $\mathrm{d}^{21}$ como en las calles y los lugares de trabajo, grupos de sus partidarios empiezan a demostrar de una manera inequivoca su manera de interpretar las consignas de lucha recibidas.

(18) Diario de Cádiz, 22 y 29 de marzo de 1934

(19) La Información, 21 de marzo de 1934

(20) La Información, 6 de $\mathrm{r}$ arzo de 1934

(21) La Información, 23 de marzo de 1934 
Una confirmación de las críticas de Martínez Barrios a la orientación derechista que estaba tomando la política gubernamental pareció proporcionarla el proyecto de ley de Amnistía, que había sido pieza clave en la campaña electoral de la coalición triunfante y cuyo texto fue presentado a las Cortes el 23 de marzo. De dicha ley se habrian de beneficiar los implicados en la sublevación de agosto de 1932, así como los monárquicos Calvo Sotelo y conde de Guadalhorce, recién elegidos diputados.

Tomando como excusa la posible exclusión de los anarcosindicalistas de dicha amnistía o según otros historiadores como acción de protesta por los malos tratos inferidos a los presos anarquistas se declaró en Zaragoza una huelga general que batiría un triste récord: seis semanas.

Zaragoza era el centro más poderoso de la Federación Anarquista Ibérica (FAI), donde se combinaba el idealismo anarquista con el gangsterismo y que iba a entrar en una testaruda prueba de fuerza con la patronal. Los hijos de los huelguistas tuvieron que ser enviados a Barcelona y Madrid para no morir de hambre. Al final, el 6 de mayo, se llegó a un acuerdo; se readmitieron los despedidos y se liberó a los presos, pero en el camino los patronos habían perdido 70 millones de pesetas y la CNT había sufrido un irreparable desgaste.

La prensa no se hace eco de estos hechos y lo único que podemos entresacar que pudiese estar relacionado con esta situación es el restablecimiento de la pena de muerte por el consejo de ministros. ${ }^{22}$

El 2 de abril en un discurso pronunciado en Sevilla, Martínez Barrios criticó ya abiertamente al gobierno, desembocando en la formación de un nuevo partido, el Radical Demócrata. Dado que Martínez barrios era gran maestre del Gran Oriente español, no es de extrañar que se atribuyese la escisión a una maniobra de la orden. En sus Memorias tanto Alcalá Zamora como Lerroux dan por buena esta versión.

Ese mismo día Azaña reagrupa a las fuerzas republicanas de izquierda en el partido de Izquierda Republicana, como fusión de Acción Republicana y del partido Radical Socialista Independiente, de Marcelino Domingo, más los republicanos gallegos de la ORGA.

No pasó desapercibido este acontecimiento para la prensa, de la cual entresacamos el siguiente párrafo: ‘Ya está constituido el grupo de izquierdas republicanas y ya ha pronunciado su primer discurso, como presidente de ese grupo, don Manuel Azaña, el cual ha dicho, entre otras cosas, que hace falta saber si en España es igual ser persona decente que no serlo. El sabrá porque hace tal pregunta: la mayoría de los españoles sabemos que lo mismo en España que fuera de ella no es igual ser decente que no serlo. La diferencia de lo que ocurre en España en

(22) La Información, 1 de abril de 1934 
comparación con otros países, es que en aquellos, a los que no lo son, no se les deja actuar en público y que el pueblo los repudia. Esto es de lógica pura y por lo tanto nos extraña la pregunta del ex-presidente de aquel Consejo que gobernaba cuando los fusilamientos de Casas Viejas. ${ }^{23}$

Abril va a ser prolijo en noticias, y en los primeros días son abundantes los editoriales referidos al tercer aniversario de la proclamación de la República. Ateniéndonos a esa letra impresa no parece que hubiesen sido tres años venturosos; mientras el Diario de Cádiz nos dice "mirad con detenimiento la obra nefasta del triste bienio Azaña-socialista y no veréis más que errores que han venido a destrozar la vida nacional. Durante ese gobierno se incendiaron iglesias y conventos, se asesinaba impunemente bajo la impasibilidad de las autoridades, se ultrajó la conciencia religiosa, se arrasaron campos, cada vez había más obreros parados que iban a sembrar el hambre y la tristeza en los hogares, las sociedades obreras abusaban de las huelgas revolucionarias, que venían a turbar la tranquilidad de España por unos días. Han pasado tres años que más bien parecen tres siglos* ${ }^{24}$; La Información advierte que *en el presente año no han sido los monárquicos ni han sido los que no siéndolos no quieren actuar en nada por estar disconformes con muchas o con todas las actuaciones, los que han restado importancia a los actos conmemorativos del tercer aniversario de la implantación del régimen; este año han sido los mismos republicanos los retraídos y de ellos los que más llamados estaban a conducirse en forma bien diferente. ¿ Cuantas casas de republicanos, de republicanos que están comiendo de la República, se han visto engalanadas durante los tres días que han durado estas fiestas oficiales?. La misma autoridad local, la genuina representación del pueblo que repartió profusamente unas octavillas pidiendo al vecindario que engalanase sus balcones y los iluminaran, no fue para iluminar ni engalanar los de su casa que, un buen urbano, constantemente a la puerta, se encargaba de no dejarla pasar inadvertida. ${ }^{25}$

Y días más tarde ya tenemos las primeras noticias sobre la tan controvertida Ley de amnistía, cuando leemos: a esta amnistía que las izquierdas parlamentarias no querían conceder, y que al ver que quisieran o no, habría que aprobarse porque era deseo de la mayoría del país,y al ver que ante tal oposición sus núcleos se iban desmembrando, han acabado por aceptar, introduciendo algunas ampliaciones que ahora le servirán de banderín para sus prosélitos, sin compre ider o no querer comprender, que si no hubiera sido por la benignidad de la Cámara, no la hubieran logrado.

La opinión española, la buena opinión española, la que quiere y ansía una España bien distinta a la que querían construir sobre tan falsos

(23) La Información, 4 de abril de 1934

(24) Diario de Cádiz, 22 de abril de 1934

(25) La Información, 17 de abril de 1934́ 
y repugnantes cimientos esos tristes hombres del célebre bienio, se siente hoy también, en parte, amnistiada. En parte nada más, porque ni en un día ni en muchos se puede terminar con todo lo podrido y con todo lo malo que sembraron en España esos sectarios ambiciosos que encerraron en un presidio al hombre que, con dos cruces laureadas sobre su honrado pecho, quiso un día salvar a España. ${ }^{26}$

En efecto, el 20 de abril se había aprobado por el Congreso la Ley de Amnistía que iba a producir una de las crisis de gobierno más delicada de la República, culminando con la dimisión de Lerroux cinco días después.

Su aprobación ya estuvo rodeada de violentos incidentes entre los diputados, y así leemos: :El señor Albiñana increpa a los socialistas y varios de estos salen de sus escaños y se dirigen contra el señor Albiñana. Este se lleva la mano forcejeando al bolsillo del pantalón y en este momento, en medio de un escándalo en que todos gritan en los escaños y van unos contra otros, en tanto los más serenos tratan de impedir las agresiones que han llegado a producirse en varios lugares de la Cámara, se ve al señor Albiñana que hace un ademán como de buscar un arma. En ese instante un vaso que parte de los socialistas vuela sobre las cabezas de los diputados y se rompe contra un banco. De los bancos de los tradicionalistas vuela otro vaso. En medio de una gran confusión, que no puede dominar el presidente ni los secretarios, que luchan a brazo partido con los diputados, vuelan también una bandeja, otro vaso que se rompe en la cabeza del tradicionalista Bau. Los diputados continúan queriéndose pegar y cuesta gran trabajo contener a los señores Negrín y Alonso ${ }^{27}$

Dos días después de aprobada la Ley, nutridos contingentes de las JAP (Juventudes de Acción Popular) se concentraron en El Escorial donde unos 25.000 jóvenes aclamaron a Gil Robles como su jefe, dando a más de uno qué pensar en la Marcha a Roma. Fueron momentos tensos, y muy críticos e incluso Gil Robles en sus Memorias ha confesado que amenazó con la posibilidad de resolver el problema de España por la fuerza. ${ }^{28}$

Son numerosas las noticias en la prensa sobre la crisis que se avecinaba, provocada, según ella por Azaña, al cual nunca se le debería permitir volver a gobernar: el verdadero origen del actual estado de cosas puede muy bien haber sido provocado por los que se ven muy de cerca de ocupar un sitio en el banquillo de la Audiencia, al lado del capitán Rojas, para responder a los asesinatos de Casas Viejas....Lo único que sabemos es que España no puede consentir la vuelta de los que están repudiados por todos.....29

(26) La Información, 21 de abril de 1934

(27) Diario de Cádiz, 21 de abril de 1934

(28) Gil Robles, José $M^{a}$. No fue posible la paz, págs. 99-120

(29) La Información, 25 y 27 de abril de 1934 
Veamos cuál es la versión de dicha crisis según un editorial del Diario de Cádiz: *El problema se plantea de este modo: el presidente de la República ha sentido grandes escrúpulos acerca de la constitucionalidad de la Ley de Amnistía y después de hacer objeciones ante el Gobierno, como este mantuviera el texto de la Ley, el presidente de la República para evitar la gravedad de una devolución a las Cortes del proyecto, accedió a la firma. Pero al mismo tiempo que sancionaba la Ley se reservaba el derecho a enviar al Congreso una nota para su archivo en la cual se reflejaban estas dudas y escrúpulos presidenciales. Naturalmente, el Gobierno no puede pasar por una discrepancia tan pública y notoria entre el jefe del Estado y las Cortes y en la sesión que celebre, inmediatamente después de sancionada la ley, quedará abierta la crisis. $x^{30}$

Mientras Lerroux seguía sin explicarse porqué Alcalá Zamora le había admitido la dimisión, ${ }^{31}$ cada vez eran más numerosas y variadas las cábalas sobre la salida a la crisis, y así mientras socialistas y republicanos de izquierda aconsejaban un gobierno republicano y disolución de las Cortes, los centristas propugnaban un nuevo ministerio presidido por Lerroux y las derechas apostaban por la continuidad pero con participación cedista.

Al final Alcalá Zamora confía en quién nadie había pensado: en Ricardo Samper, un republicano oscuro y poco conocido, sobre el que hay las más opuestas versiones: así Tussell nos dice que era superior a Lerroux en honestidad y formación", ${ }^{32}$ mientras Brenan afirma que «este gobierno era, si ello podía ser posible, más débil y estúpidamente provocador que el anterior ${ }^{33}$ y por último Preston sostiene que * Samper era un radical ineficaz, incapaz de realizar una política independiente..$^{34}$ Fue una sorpresa para todos. El Diario de Cádiz lo vio así: "Como en nuestra democuaciá la política se desenvuelve, como en la anarquía, a telón corrido, resulta que la gente se queda perpleja y se dice muy gravemente i Algo debe haber detrás de todo esto ! Y con esta explicación las tertulias de los cafés y las veladas familiares recobran su ritmo ordinario. ${ }^{35}$

Samper no sólo hubo de enfrentarse a las dificultades propias de la imposible alianza entre radicales y cedistas, sino que además se encontraría con problemas nuevos y agudos que desembocarían en los acontecimientos revolucionarios de octubre de aquel año de 1934.

(30) Diario de Cádiz, 27 de abril de 1934

(31) Lerroux, A. La pequeña historia de España, pág. 168

(32) Tussell, J. La España del siglo XX, pág. 276

(33) Brenan, G. El laberinto español, pág. 291

(34) Preston, P. La destrucción de la democracia en España, päg. 187

(35) Diario de Cádiz, 23 de abril de 1934 